\title{
Fatal Road Traffic Accidents in Niamey about 133 Cases of Death
}

Souna B Seyni*, Mohamed A, Koini M, Zirbine A Seyni, Mallam H Mahamadou, Sabo R, Foumakoye and Abassi A

Department of Orthopedics and Traumatology, Hôpital National Lamordé (CHU), Niamey, Niger

\begin{abstract}
Introduction: According to the World Health Organization, road traffic injuries caused an estimated 1.25 million deaths worldwide in the year 2010. That is one person is killed every 25 seconds.

Patients and method: This was a prospective descriptive study which was conducted over a 6 months period in the urban city of Niamey in two morgues. This study involved 133 deaths including 109 males and 28 for females.

Results: The average age of victims was 36.4 years, ranging from 3 to 85 years. Children 3 to 15 years accounted for $22(16.5 \%)$ cases. All socio-professional sectors were affected by this mortality due to RTA: so, school was the most affected with 29 cases $(21.8 \%)$. In our study head injury 58 cases $(43.6 \%)$ and polytrauma 55 cases $(41.4 \%)$ were the most basic of deaths by RTA.
\end{abstract}

Discussion: Young people are a risk to themselves and other road users as motor vehicle crashes are the leading cause of their death. Male dominance in our series is typically found in the literature.

Conclusion: The road traffic accidents mainly affect the predominantly young workforce. Mortality from RTA is a major public health both in developed countries than in developing countries.

Keywords: Road traffic accidents; Injury; Dead; Niger

\section{Introduction}

According to the World Health Organization, road traffic injuries caused an estimated 1.25 million deaths worldwide in the year 2010 That is one person is killed every 25 seconds [1]. Over a third of road traffic deaths in low- and middle-income countries are among pedestrians and cyclists. However, less than $35 \%$ of low- and middleincome countries have policies in place to protect these road users. The average rate was 17.4 per 100,000 people [1]. Road traffic accidents are major but neglected public health problems that are associated with high rates of mortality and morbidity worldwide [2]. The death rate related to RTA in Iran $(44$ per 100,000) is the highest worldwide, but motor vehicle crashes are the leading cause of death for user teenagers accounting for $40 \%$ of fatalities [3].

In Niger 8259 accidents resulting in 685 deaths were registered in 2012 [4]. These numbers are below the reality because all road traffic accidents (RTA) are not brought to the knowledge of finding service. The purpose of this study was to analyse the epidemiological and clinical aspects of death due to RTA.

\section{Patients and Method}

This was a prospective descriptive study which was conducted over a 6 months period (1 December 2013 to 31 May 2014) in the urban city of Niamey in two morgues of Niamey. This study involved 133 deaths including 109 males and 28 for females. Were included in this study all cases of death in connection with an RTA, which were recorded in one of two morgues in the city during the period of the study. Have not been included in this study all cases of death unrelated to a RTA that was recorded at one of the two morgues in the period of the study.

We collected and analysed the following parameters: the occupation, place of the accident, the time and the period of occurrence of the accident, the time between the accident and the occurrence of death, the type of road user, place of death, type of lethal lesion, type of transport, the type of collision, the concept of taking alcohol or drugs and driving permits detention.

\section{Results}

\section{Frequency}

During the study period 3865 deaths were recorded in the two morgues including a) 133 cases of deaths from injury by AC, a frequency of $3.44 \%$ of all deaths. b) 39 cases of deaths unrelated to AC trauma. c) 3693 deaths not related to trauma.

\section{Sex}

Male subjects predominated with 105 cases $(78.90 \%)$ in 28 cases (21.10\%) of female subjects with a sex ratio of 3.74 .

\section{Age}

The average age of victims was $36.4 \pm 22.1$ years, ranging from 3 to 85 years. Children 3 to 15 years accounted for 22 (16.5\%) cases. Active young adults (16-45 years old) accounted for 71 (53.4\%) cases. The age of victims varied significantly by gender $(\mathrm{p}=0.0001)$ (Table 1$)$.

\section{Profession}

All socio-professional sectors were affected by this mortality due to RTA: so, school and rural were the most affected with respectively 29 cases $(21.8 \%)$ and 26 cases (19.5\%) (Table 2).

\section{Period of the year}

December recorded the highest mortality in $30.1 \%$ of cases (Table 3).

\section{The time of occurrence of the RTA}

Most of the AC had occurred between 7 and 19 hours in 103 (77.40\%) cases. In 100 (75.2\%) cases, death occurred within 24 hours after the RTA; which in 57 (42.9\%) of the cases death occurred immediately.

*Corresponding author: Souna B Seyni, Department of Orthopedics and Traumatology, Hôpital National Lamordé (CHU), Niamey, Niger, Tel: 0022796290147/93800142; E-mail: badioseyni@yahoo.fr

Received October 13, 2016; Accepted January 23, 2017; Published January 27 2017

Citation: Seyni SB, Mohamed A, Koini M, Seyni ZA, Mahamadou HM, et al. (2017) Fatal Road Traffic Accidents in Niamey about 133 Cases of Death. Surgery Curr Res 7: 286. doi: 10.4172/2161-1076.1000286

Copyright: $\odot 2017$ Seyni SB, et al. This is an open-access article distributed under the terms of the Creative Commons Attribution License, which permits unrestricted use, distribution, and reproduction in any medium, provided the original author and source are credited. 
Citation: Seyni SB, Mohamed A, Koini M, Seyni ZA, Mahamadou HM, et al. (2017) Fatal Road Traffic Accidents in Niamey about 133 Cases of Death. Surgery Curr Res 7: 286. doi: 10.4172/2161-1076.1000286

Page 2 of 4

\begin{tabular}{|c|c|c|}
\hline Age group & Number of cases & Percent \\
\hline $1-15$ years & 22 & 16.5 \\
\hline $16-30$ years & 44 & 33.1 \\
\hline $31-45$ years & 27 & 20.3 \\
\hline $46-60$ years & 17 & 12.8 \\
\hline$>60$ years & 23 & 17.3 \\
\hline Total & $\mathbf{1 3 3}$ & $\mathbf{1 0 0 . 0}$ \\
\hline
\end{tabular}

Table 1: Death by AC/age range.

\begin{tabular}{|c|c|c|}
\hline Occupation & Number of cases & Percent \\
\hline Workers & 54 & 40.6 \\
\hline Pupils/Students & 29 & 21.8 \\
\hline Rural & 26 & 19.5 \\
\hline Housewives & 13 & 9.8 \\
\hline Unemployed & 6 & 4.5 \\
\hline Retreats & 5 & 3.8 \\
\hline Total & $\mathbf{1 3 3}$ & $\mathbf{1 0 0 . 0}$ \\
\hline
\end{tabular}

Table 2: Distribution of deaths/occupation.

\begin{tabular}{|c|c|c|}
\hline Month of the accident & Number of cases & Percent \\
\hline December & 40 & 30.1 \\
\hline March & 25 & 18.8 \\
\hline January & 22 & 16.5 \\
\hline February & 18 & 13.5 \\
\hline May & 16 & 12.1 \\
\hline April & 12 & 9 \\
\hline Total & $\mathbf{1 3 3}$ & $\mathbf{1 0 0}$ \\
\hline
\end{tabular}

Table 3: Distribution of victims depending on time of year.

\section{Possession of a driving license}

$17(47.2 \%)$ of 36 drivers had no driving license.

\section{The drunken}

$6(1.67 \%)$ cases of the 36 deceased drivers were in bad drunk.

\section{Type of user}

Pedestrians were the most affected with 55 (41.4\%) of deaths.

\section{Intra hospital mortality}

Of the 76 victims died in hospital, 56 (73.7\%) had died in surgical emergencies (Table 4).

\section{Type of personal injury}

In our study head injury 58 cases (43.6\%) and polytrauma 55 cases (41.4\%) were the most basic of deaths by RTA (Figures 1and 2). The type of fatal injury did not vary significantly by gender $(\mathrm{p}=0.09)$ (Table 5$)$.

\section{Type fatal bodily injury and time occurred RTA}

Head trauma and polytrauma with 90 (79.6\%) cases out of 113 cases were registered following RTA occurred between 7 hour and 19 hour. The type of fatal injury does not vary significantly depending on the time of RTA $(p=0.3)$.

\section{Type of collision}

Accidents auto-pedestrian type and driving backwards had led the most deaths in our series with respectively $25.6 \%$ and $21.1 \%$ (Table 6).

\section{Discussion}

Epidemiologically during the period of our study, the frequency of

\begin{tabular}{|c|c|c|}
\hline Place of death & Number of cases & Percent \\
\hline Neurosurgery & 2 & 2.6 \\
\hline Resuscitation & 9 & 11.8 \\
\hline Traumatology & 9 & 11.8 \\
\hline Surgical emergencies & 56 & 73.7 \\
\hline Total & $\mathbf{7 6}$ & $\mathbf{1 0 0}$ \\
\hline
\end{tabular}

Table 4: Distribution of deaths according to the care unit.

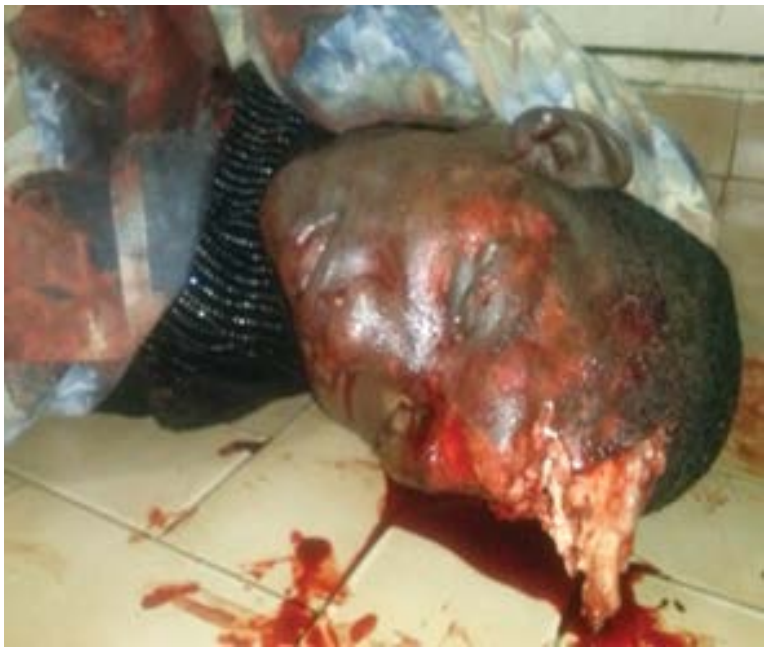

Figure 1: Moto driver died in auto-moto accident with head trauma.

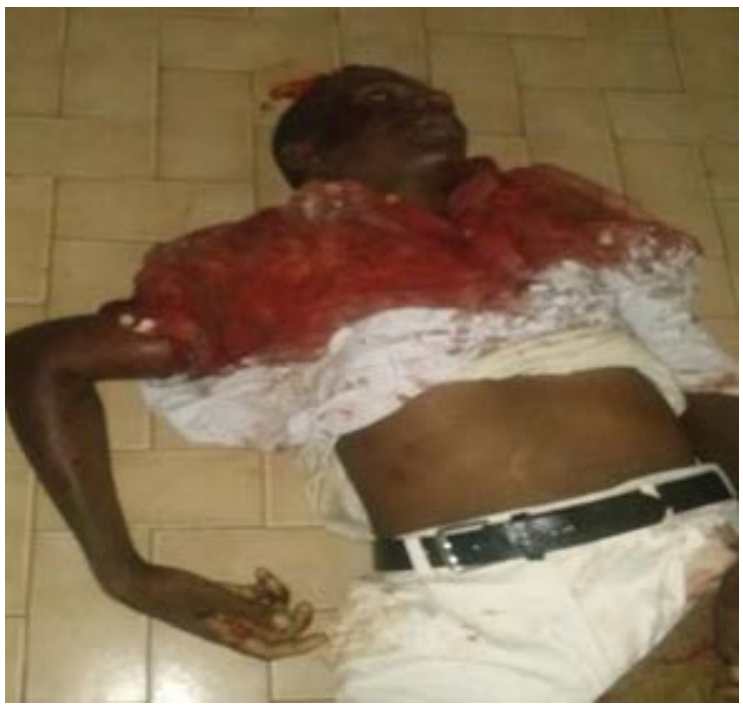

Figure 2: Pedestrian died in auto-pedestrian accident with poly trauma.

deaths related to RTA was $3.44 \%$ of all deaths. In neighboring Nigeria N'Zeguwu et al. [5] reported in their study a frequency of $7.14 \%$ of deaths related to RTA. This difference lies in the fact that Nigeria has ten times the population of our country. This phenomenon is growing and will continue in the coming years a public health problem.

So Al Reesi et al. [6] there is a link between economic growth, increasing motorization of society and the increase in road risk. We find that in our study deaths due to RTA concern mainly males aged 


\begin{tabular}{|c|c|c|}
\hline Type of injury & Number of cases & Percent \\
\hline Traumatic brain injury & 58 & 43.6 \\
\hline Polytrauma & 55 & 41.4 \\
\hline Spine injury & 9 & 6.8 \\
\hline Thoracoabdominal trauma & 8 & 6 \\
\hline External haemorrhage & 2 & 1.5 \\
\hline Poly limb fractures & 1 & 0.8 \\
\hline Total & $\mathbf{1 3 3}$ & $\mathbf{1 0 0}$ \\
\hline
\end{tabular}

Table 5: Distribution of death/type function of bodily injury.

\begin{tabular}{|c|c|c|}
\hline Type of collision & Number of cases & Percent \\
\hline Auto-pedestrian & 34 & 25.6 \\
\hline Driving backwards & 28 & 21.1 \\
\hline Moto-pedestrian & 17 & 12.8 \\
\hline Auto-moto & 14 & 10.5 \\
\hline Moto one & 13 & 9.8 \\
\hline Auto-auto & 10 & 7.5 \\
\hline Moto-moto & 8 & 6 \\
\hline Auto-bike & 5 & 3.8 \\
\hline Auto-cart & 3 & 2.3 \\
\hline Moto-cart & 1 & 0.8 \\
\hline Total & $\mathbf{1 3 3}$ & $\mathbf{1 0 0}$ \\
\hline
\end{tabular}

Table 6: Distribution of victims in collision type function.

16-30 years and $31-46$ years, totaling $53.3 \%$ of all deaths. This finding was made in 2013 by Souna et al. [4] in the same city.

Young people are a risk to themselves and other road users as motor vehicle crashes are the leading cause of their death. A thorough understanding of the most important factors associated with injury severity in crashes involving young drivers is important for designing well-targeted restrictive measures within youth-oriented road safety programs [7].

Male dominance in our series $(78.90 \%)$ is typically found in the literature: Diakite et al. [8] found $71.1 \%$ and Akhiwu et al. [9] found also $75 \%$, and the author concludes that this male dominance is explained by the hyper active male subjects who are victims of RTA in their multiple daily trips and that is why RTA lead to socio-economic consequences and work day losses. Thus the social and economic cost of these deaths related to RTA is expensive and difficult to quantify.

According to the current study, based on the network approach for the allocation of economic resources and planning of road safety strategies, calibration of injury crash rate prediction models for specific target collision type is important because of the range of harms that are caused by different collision types. From these studies it is apparent that the age and gender of drivers considered together further refines how those factors contribute to crashes. Countermeasures (structural road interventions and/or safety awareness campaigns) can be planned to reduce the highest rate of injury crash for each gender and road scenario: the awareness campaigns cannot be generalized or vague but must be organized by age and gender, because this study shows that crash dynamics alter as these factors change, with consideration for the varying psychological traits of the driver groups [10].

The responsibility of drivers is also found in a study conducted in urban areas in Spain by Ramirez et al. [11] with the involvement of drivers in $75 \%$ of cases of RTA recorded. Thus the behavior of different road users contributes to the increase of RTA.

Other cause of many death and disability in road traffic crashes is the speed at which a vehicle travels is an important determinant of injury; the faster the vehicle is travelling, the greater the energy inflicted on the occupants during a crash and the greater the injury. Excessive speed (driving faster than the posted limit or too fast for the prevailing conditions) has been found to contribute to a substantial number of crashes. It is predicted that, if the number of speeding drivers is reduced, both the likelihood and severity of a crash will be lowered. Therefore, interventions aimed at reducing traffic speed are considered essential to preventing road injuries and deaths. The enforcement of safe speeds with speed cameras and associated automated devices is one such measure [12].Thus deaths due to RTA also affect developed countries than developing countries.

In the United States a study conducted about gender differences and similarities in injury severity risk of young drivers permitted to identify many factors which increase young female drivers' injury severity and young male drivers' injury severity were identified [13].

According to another study conducted in United States (Colorado) showed that motor vehicle crashes are the leading cause of teenagers' death, accounting for $40 \%$ of fatalities. Fatal motor vehicle crashes involving novice drivers are characterized by speeding, recklessness, single-vehicle and rollover crashes, and traffic law violations, suggesting that novice drivers bear considerable responsibility for their fatal crashes. Moreover, almost half of 16-year-old drivers involved in fatal motor vehicle crashes were not wearing their safety belts. [14].

In Portugal, Carlos et al. reported that their study shows the contribution of critical slopes and vehicle rollover towards fatal injuries and highlights the importance of introducing the "forgiving roadside" concept to mitigate rollover crash severity in Portuguese freeways. The study also indicates the importance of protecting errant vehicles particularly in horizontal curves, as these are linked with fatalities [15]

And the epidemiological profile of RTA is a male young adult but what is the explanation? And the author to answer: this mortality of adolescents is found in our study (pupils and students, and youth from rural) alone account for $41.3 \%$ of deaths due to RTA and which the majority of them without driving license or without no concept of road traffic rules and take the most foolish risks. Also, young people in rural available from this means of transport as soon as their financial means allow them but without any driving experience either in country and even more so in urban areas easily exposing to traumatic jeopardy. This drive increasingly growing company is the result of the availability of two-wheeled motors from Asia. This accessibility that parents provide more and more to the big cylinder motorcycles to young children who have not reached the legal age to drive, with the sole aim to reward school performance of their children. In order to show their joy and sensation seeking comfort especially during processions a wedding, this explains the occurrence of fatal accidents rush hour traffic and December with the year-end holidays.

Clinically the lethal lesion in our patient was in most cases due to head trauma in $43.6 \%$ of cases. This result is similar to that of Ouattara et al. [16] reported that $48 \%$ of cases. This series in its high lethality is related to the severity of lesions on the one hand and secondly the lack of protective equipment harbor like wearing helmets or seat belts.

In our series many deaths occurred on the accident place (42.8\%) this finding is consistent with that of Diakite et al. [8] who reported $42.67 \%$ cases of deaths at the place of accident. This is explained by the severity of injuries, emergency delay and lack of qualified personnel especially in rural areas. 
Citation: Seyni SB, Mohamed A, Koini M, Seyni ZA, Mahamadou HM, et al. (2017) Fatal Road Traffic Accidents in Niamey about 133 Cases of Death. Surgery Curr Res 7: 286. doi: 10.4172/2161-1076.1000286

Pedestrians were the most victims of users with $41.4 \%$; which is consistent with the result of Souna et al. [4] explaining the vulnerability of this category of the highway users especially children.

\section{Conclusion}

Mortality from RTA is a major public health both in developed countries than in developing countries. The road traffic accidents mainly affect the predominantly young workforce. Thus efforts must converge towards a better public education, conducting awareness to reduce the number of victims due to RTA.

\section{References}

1. World Health Organisation (2015) Global status report on road safety 2015.

2. Bakhtiyari M, Delpisheh A, Monfared AB, Kazemi-Galougahi MH, Mehmandar MR, et al. (2015) The road traffic crashes as a neglected public health concern; an observational study from Iranian population. Traffic Inj Prev 16: 36-41.

3. SargaziA, Sargazi A, Nadakkavukaran Jim PK, Danesh HA, Sargolzaee Aval F, et al. (2016) Economic burden of road traffic accident: Report from a single center from south eastern Iran. Bull Emerg Trauma 4: 43-47.

4. Souna (2016) Road accidents in Niamey: Epidemiological and clinical aspects of 1000 cases. Ann UAM.

5. N'Zeguwu MA, Banjo AA, Akhiwu W, Aligbe JU, Nzegwu CO ( 2008) Morbidity and mortality among road users in Benin-City, Nigeria. Ann Afr Med 7: 102-106.

6. Al-Reesi H, Ganguly SS, Al-Adawi S, Laflamme L, Hasselberg M, et al. (2013) Economic growth, motorization, and road traffic injuries in the Sultanate of Oman. Traffic Inj Prev 14: 322-328.
7. Weiss HB, Kaplan S, Prato CG (2014) Analysis of factors associated with injury severity in crashes involving young New Zealand drivers. Accid Anal Prev 65: $142-155$.

8. Diakite AK, Anzilania, Diaby, Camara ND (2005) Mortality by road accident at the Donka University Hospital. Mali Medical 10: 17-19.

9. Akhiwu WO, Nwafor CC, Igbe AP (2013) A 20 year retrospective analysis of medicolegal deaths in a tertiary hospital setting in Nigeria. Niger J Clin Pract 16: 535-539.

10. Russo F, Biancardo SA, Dell Acqua G (2014) Road safety from the perspective of driver gender and age as related to the injury crash frequency and road scenario. Traffic Inj Prev 15: 25-33.

11. Ramírez BA, Izquierdo FA, Fernandez CG, Mendez AG (2009) The influence of heavy goods vehicle traffic on accidents on different types of Spanish interurban roads. Accid Anal Prev 41: 15-24.

12. Wilson C, Willis C, Hendrikz JK, Le Brocque R, Bellamy N (2010) Speed cameras for the prevention of road traffic injuries and deaths. Cochrane Database Syst Rev.

13. Amarasingha N, Dissanayake S (2014) Gender differences of young drivers on injury severity outcome of highway crashes. J Safety Res 49: 113-120.

14. Gonzales MM, Dickinson LM, DiGuiseppi C, Lowenstein SR (2005) Student drivers: A study of fatal motor vehicle crashes involving 16-year-old drivers. Ann Emerg Med 45: 140-146.

15. Carlos Roque, Filipe Moura, JoãoLourençoCardoso (2015) Detecting unforgiving roadside contributors through the severity analysis of ran-off-road crashes. Accid Anal Prev 80: 262-273.

16. Ouattara O, Moh N, Kouame B, Dieth A, Dick R, et al (2001) Morbidity and mortality of 1894 road accidents in children at Yopougon University Hospital in Abidjan. MedAfrNoire 48: 11-14. 